\title{
Nighttime TEC Variation Analysis of Klobuchar Model Based on IGS Data in China
}

\author{
Yunzhen YANG ${ }^{1,2}$, Lilong $\operatorname{LIU}^{1,2 *}$, Liangke HUANG ${ }^{1,2 *}$, Qingtong WAN ${ }^{1,2}$, Shu WANG ${ }^{1,2}$ \\ 1. College of Geomatics and Geoinformation, Guilin University of Technology, Guilin 541004, China \\ (yangyz_117, hn_liulilong, lkhuang666)@163.com \\ 2. Guangxi Key Laboratory of Spatial Information and Geomatics, Guilin 541004, China
}

KEY WORDS: Klobuchar Model, Solar activity, Nighttime, Ionosphere delay, TEC, Precision analysis

\begin{abstract}
:
In order to further study the variation characteristics of the nighttime ionospheric accuracy of the Klobuchar model and the correlation between the nighttime ionospheric accuracy of the Klobuchar model and solar activity intensity. In this paper, a method for comparative analysis on solar activity intensity in the high, medium and low solar activity years has been proposed. The GIM provided by the IGS Center from 2008 to 2018 are treated as reference values to analyze the nighttime accuracy of the Klobuchar model for annual, seasonal, and monthly changes in high solar activity, medium solar activity and low solar activity. The results are: (1) The nighttime accuracy of the Klobuchar model is best in the medium solar activity, followed in the low solar activity and the worst in the high solar activity. (2) The Bias and RMS of the Klobuchar model at nighttime had obviously semi-annual and seasonal variations in high and medium solar activity. (3) The nighttime accuracy of the Klobuchar model did not vary with Bias and RMS changes at nighttime.
\end{abstract}

\section{INTRODUCTION}

Ionospheric delay is one of the mainly error sources in Global Navigation Satellite System (GNSS). The delay can be up to 50 meters in the zenith direction, and can be up to 150 meters in the direction of the ground $[1,2]$. Therefore, it is important to eliminate the ionospheric delay error reasonably and effectively. The ionospheric delay in satellite navigation and positioning systems can be significantly eliminated by using dual-frequency or multi-frequency methods. But for single-frequency GNSS users, the Klobuchar model is the most effective way to correct for the ionospheric delay.

The Klobuchar model can calculate ionospheric delay data easily for a broadcast ephemeris, satellite elevation, and satellite azimuth only. Because Klobuchar model can compute the ionospheric delay easily and conveniently, they are widely

\footnotetext{
* Corresponding author.
}

used in single-frequency receivers. However, the Nighttime Vertical Total Electron Content (NVTEC), as a significant parameter in Klobuchar model, has been commonly set to a constant value of 9.23TECU, which will result in $20-30 \%$ positioning error. Therefore, in order to meet the requirements of single-frequency users for the accuracy of navigation and position, many researchers are committed to the correction of the nighttime ionospheric VTEC. ZHU et al. [3] uses the solar flux density to revise the nighttime ionospheric VTEC. ZHAO et al. [4] considers that the ionospheric VTEC is closely related to solar activity, then, the nighttime VTEC is corrected by the number of sunspots that characterize the degree of solar activity. WANG et al. [5] considering the nighttime ionospheric delay with the variation of the latitude quadratic parabola, a 10-parameter model is established. Cai et al. [6] the nighttime ionospheric delay is regarded as the cosine function of time, and an 11-parameter regional model is established. ZHANG et al. and $\mathrm{XU}$ et al. $[7,8]$ considering the linear variation of the nighttime ionospheric delay with latitude, the improved Klobuc 
-har model of China region with 14 parameters and 13 parameters has been established successively. The characteristics of daily variation and seasonal variation with the ionospheric VTEC of Curtin University in 2013 and 2014 were analyzed by using the dual-frequency BeiDou GEO data, then, an 16-parameters regional model was established by dividing the time into three sections and regarded it as a linear change [9]. LIU et, al. [10] establishes Klobuchar-like models that can be used for different scale regions, which depending on the high-order changes of temporal and latitude. All of the above methods can improve the nighttime accuracy of the Klobuchar model, but few documents analyze the nighttime accuracy of the model from these aspects, such as ionospheric electron content varies at rates of season, semiyear, year, and solar activity cycle on time series.

China is located in the middle and low latitudes of the northern hemisphere. It is of great significance to study the nighttime accuracy of the Klobuchar model in China. Therefore, in this paper, the high-precision GIM data from 2008-2018 provided by the IGS Center was used as a reference value to study the accuracy variation of the Klobuchar model in the nighttime during the 24th solar activity cycle and the influencing factors, and provide a reference for the improvement and regionalization of the Klobuchar model.

\section{THE IONOSPHERIC MODEL}

\subsection{Klobuchar Model}

The Klobuchar model is simplified by the Bent ionospheric empirical model [11]. It has the advantages of simple structure and convenient calculation. It can provide the ionospheric delay correction of the single-frequency receiver for the GPS broadcast ephemeris. The mathematical formula of the Klobuchar model is given by Eq. (1):

$T=\left\{\begin{array}{l}A_{1}+A_{2} \cos \left[\frac{2 \pi\left(t-A_{3}\right)}{A_{4}}\right],\left|t-A_{3}\right| \leq \frac{A_{4}}{4} \\ A_{1},\left|t-A_{3}\right| \geq \frac{A_{4}}{4}\end{array}\right.$

Where, $T$ is the correction of ionospheric time delay, $A_{1}$ is the nighttime delay term, which usually set to $5 \mathrm{~ns}$. $A_{3}$ is the initial phase, which is 50400s. $A_{2}$ and $A_{4}$ are the amplitude of the day cosine function and the period of the day cosine function, respectively. $t$ indicates the position corresponding to the initial phase.

\subsection{The Global Ionospheric Map}

The Global Ionospheric Map (GIM), one of the main products of IGS derived from GPS measurement, describes the ionosphere image in longitude, latitude and time. The maps cover latitudes from $-87.5^{\circ}$ to $87.5^{\circ}$ in step of $2.5^{\circ}$ and longitudes from $-180^{\circ}$ to $180^{\circ}$ in step of $5^{\circ}$. The sampling interval is $2 \mathrm{~h}$. As an important part of GNSS precision products, IGS GIM includes three types of products: Final GIM, Fast GIM and Predictive GIM. Among them, the final GIM of IGS is weighted according to the GIM provided by each analysis center. The research shows that the data has high precision and can reflect the irregular changes of the ionosphere [12], and exchanged in the (IONEX) format.

\section{THE DATA SELECTION AND PROCESSING METHOD}

\subsection{The Source of Data}

The F10.7 solar radio flux, provided by the National Geophysical Data Center (NGDC) of the National Oceanic and Atmospheric Administration (NOAA), can better reflect the level of solar activity [13]. In this study, we will research the accuracy and residuals of Klobuchar model in the night under different solar activity levels. Figure 1 is a time-series variation of the F10.7 solar radio flux from January 2008 to December 2018. For figure1, we can determine the high (2012-2014) solar activity, medium (2010-2011, 2015-2016) solar activity and low $(2008-2009,2017-2018)$ solar activity.

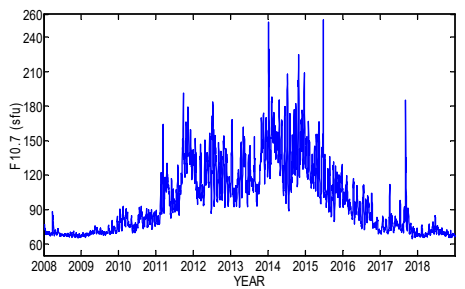

Figure 1. Daily average of $10.7 \mathrm{~cm}$ Solar Radio Flux

\subsection{The Index of Accuracy Evaluation}


The GIM data, provided by IGS has higher accuracy than 2 4TECU in different solar activity cycles around the world, meeting the research needs [14]. In this paper, the TEC value provided by the high-precision GIM ionospheric model is used as a reference value. and three statistical indices, including the Precision (Pre), Bias and Root Mean Square (RMS) are introduced for validation. The statistical indices are defined in Eqs. (2)-(4).

$$
\begin{aligned}
& \operatorname{Pr} e=\left(1-\frac{X_{m}^{M}-X_{m}^{R}}{X_{m}^{R}}\right) \times 100 \% \\
& \operatorname{Bias}=\frac{1}{N} \sum_{i=1}^{N}\left(\mathrm{X}_{m}^{M}-\mathrm{X}_{m}^{R}\right) \\
& R M S=\sqrt{\frac{1}{N} \sum_{i=1}^{N}\left(\mathrm{X}_{m}^{M}-\mathrm{X}_{m}^{R}\right)^{2}}
\end{aligned}
$$

Where $X_{m}^{M}$ is the nighttime VTEC value of the Klobuchar model, $X_{m}^{R}$ is the reference value, and $\mathrm{N}$ is the number of samples.

\section{RESULTS AND DISCUSSION}

\subsection{Annual Variation Characteristics of the nighttime accuracy of Klobuchar model}

The nighttime average annual accuracy of the Klobuchar model for each grid point from 2008 to 2018 in China was calculated according to Eq. (2). The statistics in Table 1 showed the nighttime average annual accuracy, the nighttime maximum average annual accuracy and the nighttime minimum average annual accuracy. It can be seen that the nighttime average accuracy of the Klobuchar model varies with the solar activity. Contrary to the variations in ionospheric TEC, the nighttime accuracy of the Klobuchar model was highest in 2010, the lowest in 201. In terms of the fluctuation range of the nighttime average accuracy of the Klobuchar model, the fluctuation of the nighttime average annual accuracy is greater than the fluctuation range of the medium solar activity and the high solar activity. Figure 2 shows the variation of the annual average accuracy of the Klobuchar model from 2008 to 2018 with latitude and longitude.

Tab.1 Statistics results of Nighttime Accuracy of Klobuchar Model by Using GIM data from 2008 to 2018

\begin{tabular}{cllllllllllll}
\hline YEARS & & 2008 & 2009 & 2010 & 2011 & 2012 & 2013 & 2014 & 2015 & 2016 & 2017 & 2018 \\
\hline \multirow{4}{*}{ Pre } & MAX & 0.82 & 0.81 & 0.85 & 0.72 & 0.72 & 0.71 & 0.66 & 0.71 & 0.81 & 0.88 & 0.85 \\
& MIN & 0.03 & 0.04 & 0.47 & 0.45 & 0.36 & 0.33 & 0.27 & 0.26 & 0.04 & -0.34 & -0.30 \\
& Mean & 0.64 & 0.62 & 0.77 & 0.62 & 0.59 & 0.57 & 0.50 & 0.57 & 0.68 & 0.69 & 0.60 \\
\hline
\end{tabular}

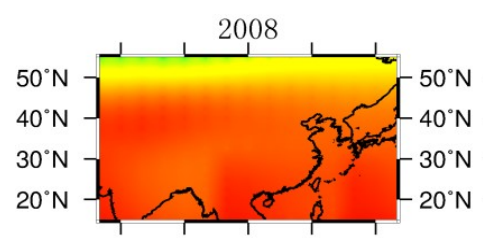

$75^{\circ} \mathrm{E} 90^{\circ} \mathrm{E} 105^{\circ} \mathrm{E} 120^{\circ} \mathrm{E} 135^{\circ} \mathrm{E}$ 2012

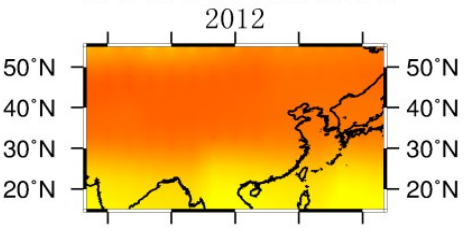

$75^{\circ} \mathrm{E} 90^{\circ} \mathrm{E} 105^{\circ} \mathrm{E} 120^{\circ} \mathrm{E} 135^{\circ} \mathrm{E}$

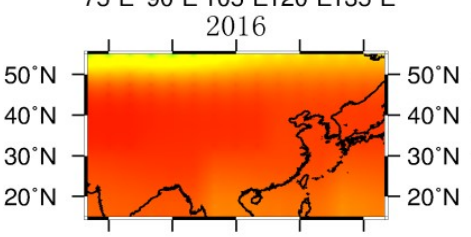

$75^{\circ} \mathrm{E} 90^{\circ} \mathrm{E} 105^{\circ} \mathrm{E} 120^{\circ} \mathrm{E} 135^{\circ} \mathrm{E}$

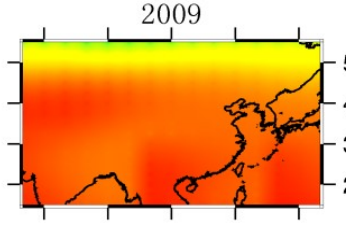

$75^{\circ} \mathrm{E} 90^{\circ} \mathrm{E} 105^{\circ} \mathrm{E} 120^{\circ} \mathrm{E} 135^{\circ} \mathrm{E}$ 2013

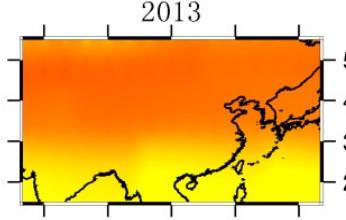

$75^{\circ} \mathrm{E} 90^{\circ} \mathrm{E} 105^{\circ} \mathrm{E} 120^{\circ} \mathrm{E} 135^{\circ} \mathrm{E}$

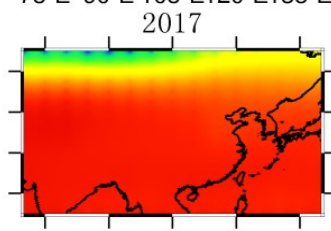

$75^{\circ} \mathrm{E} 90^{\circ} \mathrm{E} 105^{\circ} \mathrm{E} 120^{\circ} \mathrm{E} 135^{\circ} \mathrm{E}$

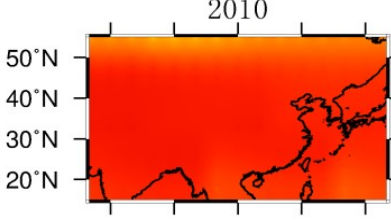

$75^{\circ} \mathrm{E} 90^{\circ} \mathrm{E} 105^{\circ} \mathrm{E} 120^{\circ} \mathrm{E} 135^{\circ} \mathrm{E}$ 2014

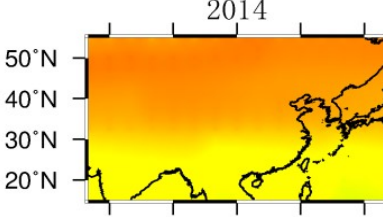

$75^{\circ} \mathrm{E} 90^{\circ} \mathrm{E} 105^{\circ} \mathrm{E} 120^{\circ} \mathrm{E} 135^{\circ} \mathrm{E}$

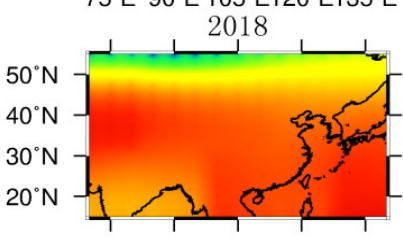

$75^{\circ} \mathrm{E} 90^{\circ} \mathrm{E} 105^{\circ} \mathrm{E} 120^{\circ} \mathrm{E} 135^{\circ} \mathrm{E}$

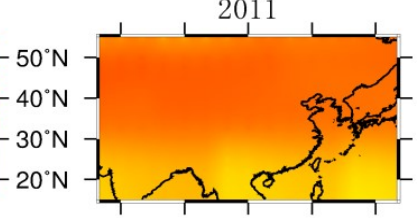

$75^{\circ} \mathrm{E} 90^{\circ} \mathrm{E} 105^{\circ} \mathrm{E} 120^{\circ} \mathrm{E} 135^{\circ} \mathrm{E}$

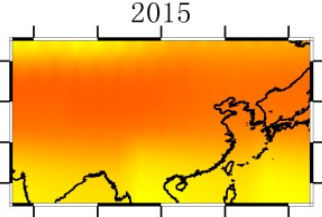

$75^{\circ} \mathrm{E} 90^{\circ} \mathrm{E} 105^{\circ} \mathrm{E} 120^{\circ} \mathrm{E} 135^{\circ} \mathrm{E}$

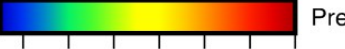

$\begin{array}{lllllllll}-0.2 & 0.0 & 0.2 & 0.4 & 0.6 & 0.8 & 1.0\end{array}$

Fig.2 Annual accuracy of the Klobuchar model during high, medium and low solar activities 
For figure 2, we can obtained that the nighttime average accuracy of the Klobuchar model varies with latitude is difference at different solar activity, and the nighttime average annual accuracy is the best in 2010. In the high solar activity (2012-2014), the nighttime average accuracy of the Klobuchar model is higher in the mid-latitude region than in the low latitude region. In the medium solar activity (2010-2011, 2015-2016), the nighttime average accuracy of the Klobuchar model is higher in the mid-latitude region than in the low latitude region in 2011. The nighttime average annual accuracy is better at $30^{\circ} \mathrm{N} \sim 50^{\circ} \mathrm{N}$ in 2015 , and the nighttime average annual accuracy is lower in the north $50^{\circ} \mathrm{N}$ in 2016 . In the low solar activity (2008-2009, 2017-2018), the nighttime average accuracy of the Klobuchar model is decrease with the increasing of latitudes. This further indicates that the average annual accuracy at night is negatively correlated with the degree of solar activity.

The nighttime average annual Bias and average annual RMS of the Klobuchar model during different solar activities are shown in Table 2. It can be found that the nighttime average annual Bias and the maximum nighttime average annual Bias of the Klobuchar model are largest in the high solar activity, followed by the medium solar activity and the low solar activity. The nighttime average annual Bias of the Klobuchar model is -9.01TECU, -3.72TECU and 1.72TECU in high solar activity, medium solar activity and low solar activity, respectively. The maximum nighttime average annual Bias of Klobuchar model is -22.00TECU, -11.41TECU and -0.75TECU during high, medium and low solar activity, respectively. The nighttime minimum average annual of the Klobuchar model shows a significant negative deviation between the medium solar activity and the low solar activity, which are 1.73TECU and 4.46TECU, respectively, while the minimum average annual Bias is $0.91 \mathrm{TECU}$ in the high solar activity. In addition, the nighttime average annual RMS of the Klobuchar model is 11.15 TECU, 6.79 TECU and 2.50 TECU in the high, medium and low solar activity, respectively. While the maximum average annual RMS is 24.08 TECU in the high solar activity. Those further shows that the nighttime accuracy of the Klobuchar model in medium solar activity is better than that in the low and high solar activity.

Figure 3 shows the variation of the average annual Bias and average annual RMS of the Klobuchar model with latitude during the high, medium and low solar activity. The nighttime average annual Bias and average annual RMS of the Klobuchar model are not significantly variation with latitude in the low solar activity, and the range of variation is stable within the 5 TECU, and the average annual Bias were negative in all the latitudes. In the high and medium solar activity, the average annual Bias and average annual RMS of the Klobuchar model show a firstly increase and then decrease with the increasement of latitudes. It is the maximum at $20^{\circ} \mathrm{N}$, and the variation of the nighttime average annual Bias and annual RMS is relatively stable in $35^{\circ} \mathrm{N}-55^{\circ} \mathrm{N}$. The main reason is that the ionospheric TEC is more activity in low latitudes. With the increase of latitude, the ionospheric TEC is significantly reduced, and there are obvious equatorial anomalies.

Tab.2 Statistics results of Nighttime Accuracy of Klobuchar Model by Using GIM data in different solar activity

\begin{tabular}{lllll}
\hline $\begin{array}{l}\text { solar } \\
\text { activity }\end{array}$ & & high & medium & low \\
\hline \multirow{4}{*}{ bias } & MAX & 0.91 & 1.73 & 4.46 \\
& MIN & -22.00 & -11.41 & -0.75 \\
& Mean & -9.01 & -3.72 & 1.72 \\
\multirow{2}{*}{ RMS } & MAX & 24.08 & 15.08 & 4.71 \\
& MIN & 5.07 & 3.44 & 1.59 \\
\hline
\end{tabular}

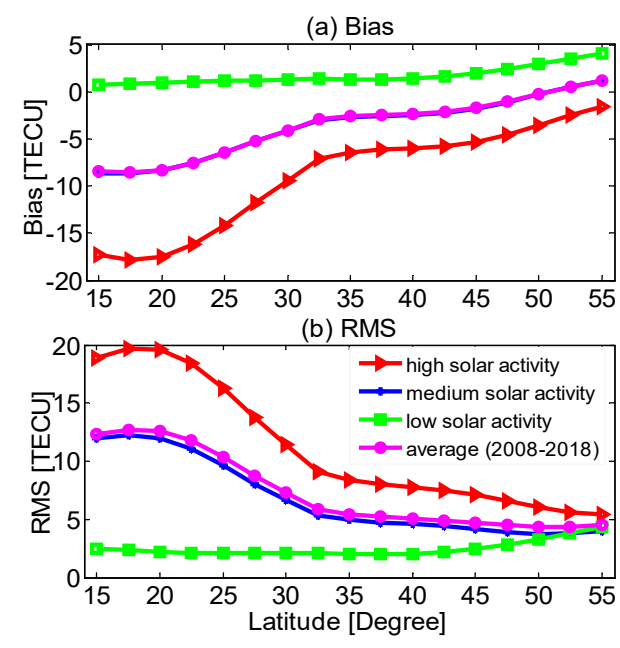

Fig.3 Bias and RMS during high, medium and low solar activities

\subsection{Seasonal variation characteristics of the nighttime accuracy of Klobuchar model}

The year of March, April and May is defined as spring, June, 
July and August are defined as summer, September, October and November are defined as autumn, and December, January and February are defined as winter. We analyzed the nighttime average accuracy of the Klobuchar model in China, where during the high, medium and low solar activity. The season average accuracy during high, medium and low solar activities were showed in Figure 4. It can be seen that in the low and medium solar activity, the nighttime season average accuracy is best in summer, while it is worst in winter. The nighttime season average accuracy of the Klobuchar model is decreased with the increasing of the latitudes in the low solar activity years. During the medium solar activity, the nighttime season average accuracy of Klobuchar model in $30^{\circ} \mathrm{N}-55^{\circ} \mathrm{N}$ is better than that in $15^{\circ} \mathrm{N}-30^{\circ} \mathrm{N}$ with the spring. While the nighttime season average accuracy is the best in $30^{\circ} \mathrm{N}-47^{\circ} \mathrm{N}$ at autumn and winter. In high solar activity, the nighttime season average accuracy of Klobuchar model was the best in $30^{\circ} \mathrm{N}-55^{\circ} \mathrm{N}$, while it decreased with the decreasing of the latitudes in the south of $30^{\circ} \mathrm{N}$ and decreased with the decreasing of the latitudes in the north of $50^{\circ} \mathrm{N}$. The nighttime season average accuracy of the Klobuchar model increased with the increasing of the latitudes in the other seasons.

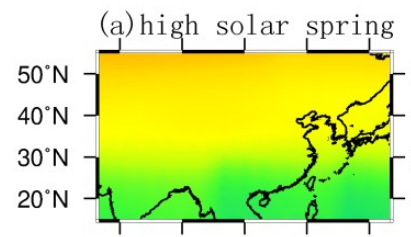

$75^{\circ} \mathrm{E} 90^{\circ} \mathrm{E} 105^{\circ} \mathrm{E} 120^{\circ} \mathrm{E} 135^{\circ} \mathrm{E}$
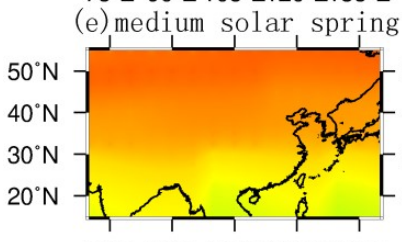

$75^{\circ} \mathrm{E} 90^{\circ} \mathrm{E} 105^{\circ} \mathrm{E} 120^{\circ} \mathrm{E} 135^{\circ} \mathrm{E}$ (i) low solar spring

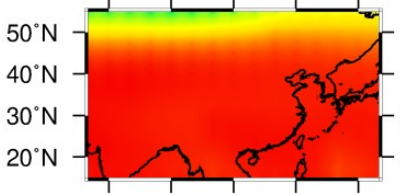

$75^{\circ} \mathrm{E} 90^{\circ} \mathrm{E} 105^{\circ} \mathrm{E} 120^{\circ} \mathrm{E} 135^{\circ} \mathrm{E}$

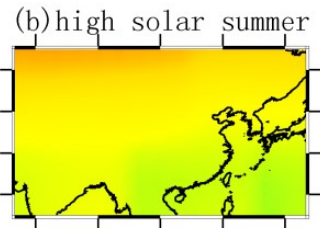

$75^{\circ} \mathrm{E} 90^{\circ} \mathrm{E} 105^{\circ} \mathrm{E} 120^{\circ} \mathrm{E} 135^{\circ} \mathrm{E}$

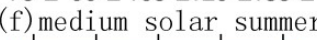

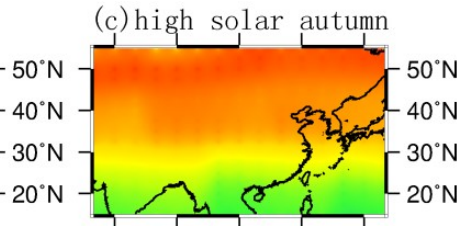

$75^{\circ} \mathrm{E} 90^{\circ} \mathrm{E} 105^{\circ} \mathrm{E} 120^{\circ} \mathrm{E} 135^{\circ} \mathrm{E}$

(g)medium solar autumn

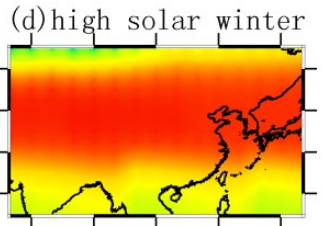

$75^{\circ} \mathrm{E} 90^{\circ} \mathrm{E} 105^{\circ} \mathrm{E} 120^{\circ} \mathrm{E} 135^{\circ} \mathrm{E}$

(h) medium solar winter
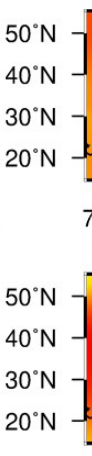

$75^{\circ} \mathrm{E} 90^{\circ} \mathrm{E} 105^{\circ} \mathrm{E} 120^{\circ} \mathrm{E} 135^{\circ} \mathrm{E}$ (j) low solar summer

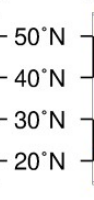

$75^{\circ} \mathrm{E} 90^{\circ} \mathrm{E} 105^{\circ} \mathrm{E} 120^{\circ} \mathrm{E} 135^{\circ} \mathrm{E}$

(k) low solar autumn

$75^{\circ} \mathrm{E} 90^{\circ} \mathrm{E} 105^{\circ} \mathrm{E} 120^{\circ} \mathrm{E} 135^{\circ} \mathrm{E}$
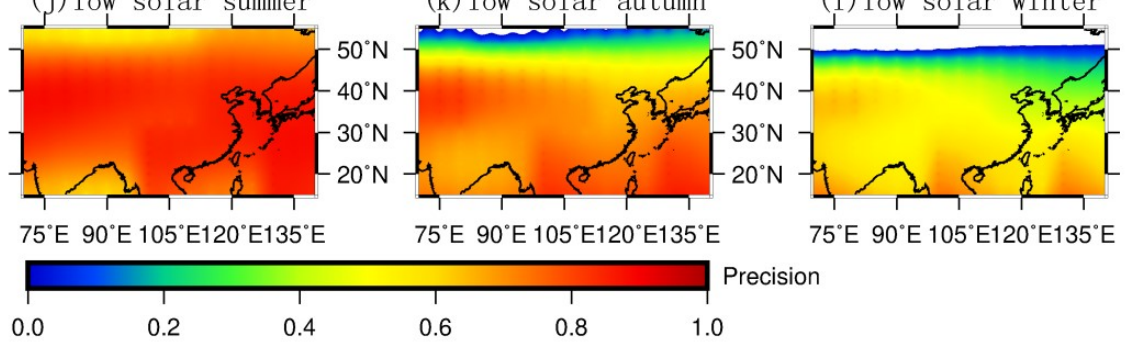

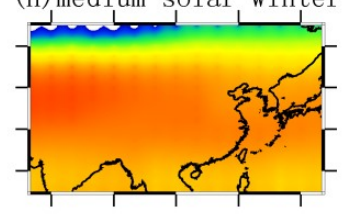

$75^{\circ} \mathrm{E} 90^{\circ} \mathrm{E} 105^{\circ} \mathrm{E} 120^{\circ} \mathrm{E} 135^{\circ} \mathrm{E}$ (1) low solar winter

Fig.4 Season average accuracy of Klobuchar model during high, medium and low solar activities

The relationship between the nighttime seasonal average Bias and the latitude, and between the nighttime seasonal average RMS and the latitude in China was further analyzed. In this paper, the latitudes in step of $5^{\circ}$ was defined. Form figure 5(d) to figure $5(\mathrm{f})$, it can be seen that in the high and medium solar activity, the nighttime TEC value of Klobuchar model setting mostly underestimates the actual ionospheric TEC value, and its underestimation decreases with the increasing latitudes. Compared with the GIM, the nighttime TEC setting of the Klobuchar model in winter overestimates in $45^{\circ} \mathrm{N}-55^{\circ} \mathrm{N}$ during the high solar activity and in $30^{\circ} \mathrm{N} \sim 55^{\circ} \mathrm{N}$ during the medium solar activity. In the low solar activity, except for the spring in $15^{\circ} \mathrm{N}-20^{\circ} \mathrm{N}$, it showed that the nighttime TEC of Klobuchar model has an obviously overestimation, and the overestimation is significantly larger with the increased of the latitudes in autumn and winter. In addition, Form figure 5(a) to figure 5(c), we can found that the nighttime average RMS of the Klobuchar model is greater in the low latitudes than in the high latitudes during high and medium solar activity. While the nighttime average RMS of the Klobuchar model increased with the increasing of the latitudes during the low solar activity.

\subsection{Monthly variation characteristics of the nighttime accuracy of Klobuchar model}

Figure 6 shown that the nighttime monthly average accuracy, monthly average Bias and monthly average RMS of the Klobuchar model for high, medium and low solar activity are 
(a) low solar activity

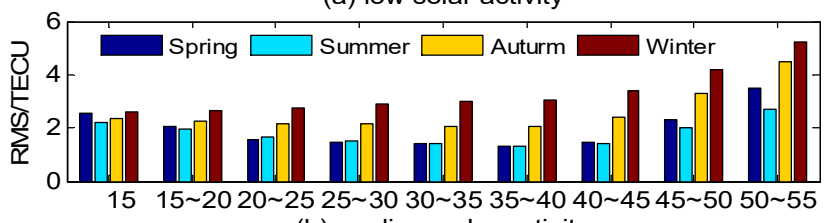

(b) medium solar activity

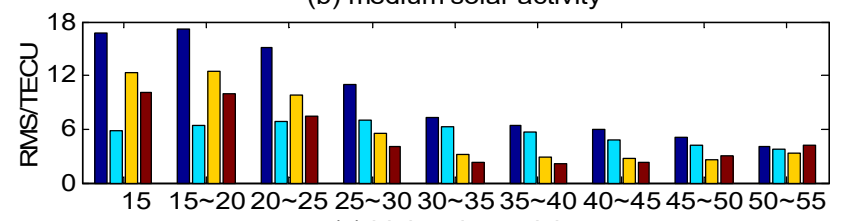

(c) high solar activity

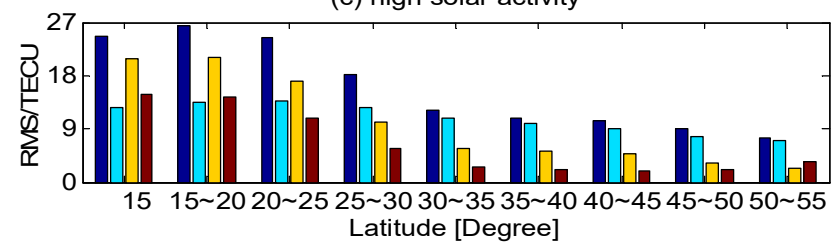

(d) low solar activity

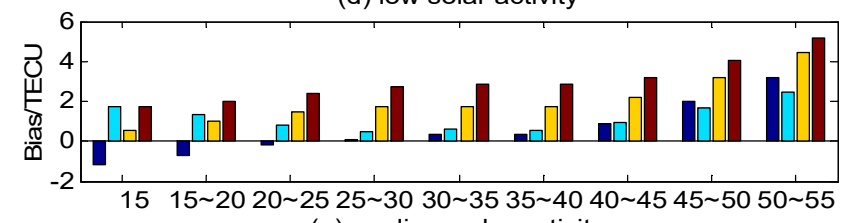

(e) medium solar activity

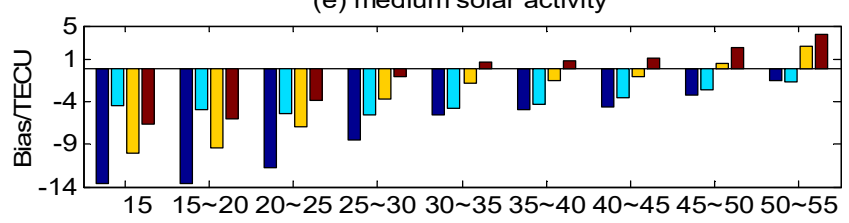

(f) high solar activity

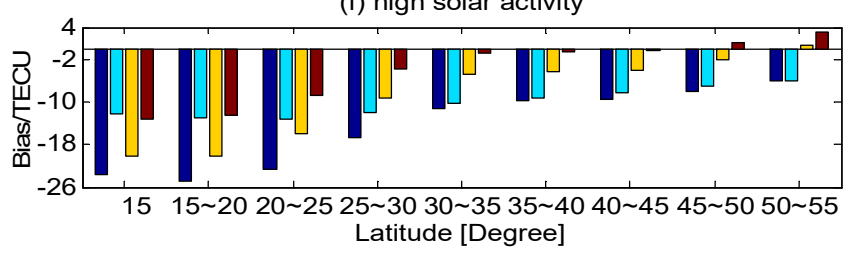

Fig.5 Season average Bias and RMS of Klobuchar model during high, medium and low solar activities

(a) high solar activity

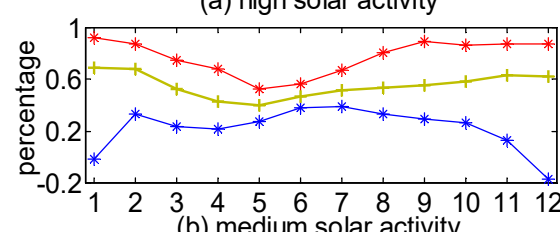

(b) medium solar activity

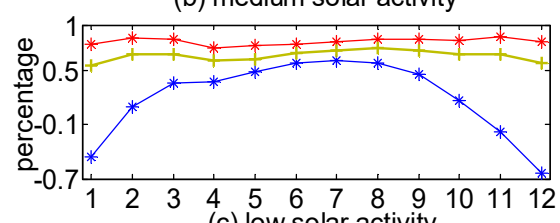

(c) low solar activity

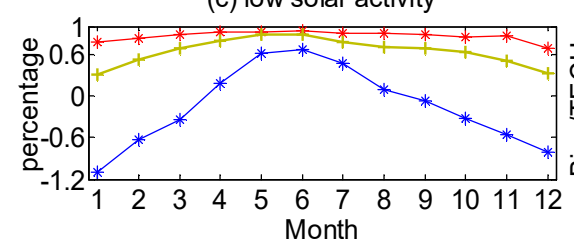

(d) high solar activity

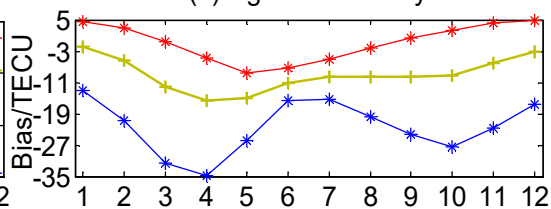

(e) medium solar activity

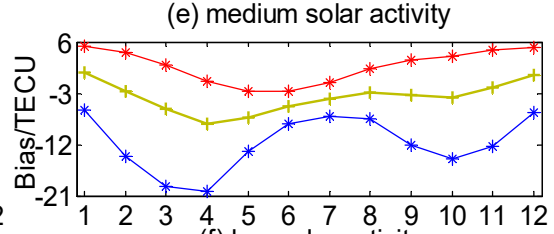

(f) low solar activity

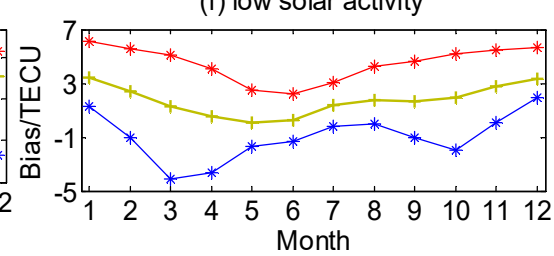

(g) high solar activity

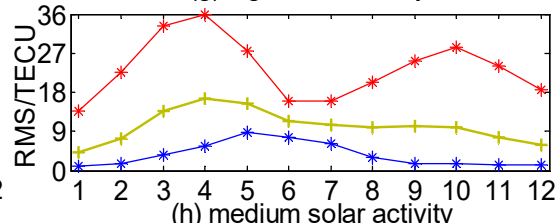

(h) medium solar activity
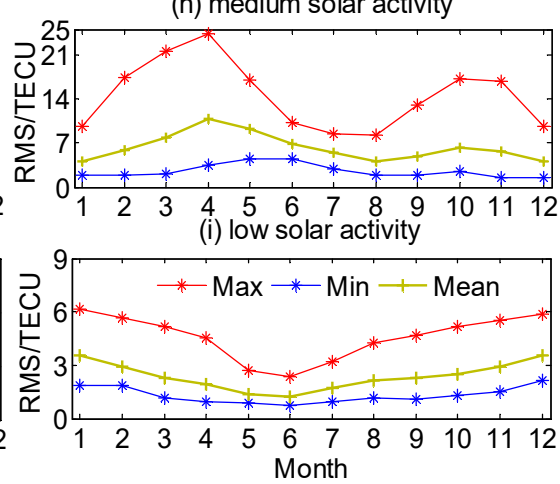

Fig.6 Correction, Bias and RMS of each month during high, medium and low solar activities

analyzed in months, as shown in Figure 6.

Figure 6(a) to figure 6 (c) shows that the nighttime monthly average accuracy of the Klobuchar model is inconsistent with the change of the month during high, medium and low solar activity. The nighttime monthly average accuracy of the Klobuchar model is the worst in April and May during the high and medium solar activity, while it is the best in May and June during the low solar activity. In terms of the range of nighttime accuracy, Klobuchar model shows a change in the range of nighttime accuracy from January to December, which is firstly decreased and then increased, and its variation range is the smallest in June. In terms of the levels of solar activity, the range of nighttime accuracy variation of the Klobuchar model is the largest in the low solar activity, followed by the medium solar activity, and it is smallest in the high solar activity.

From figure 6(d) to figure 6(f), we can found that the upper limit of nighttime monthly average Bias and the monthly average Bias of the Klobuchar model have an obviously semi-annual variations. The upper limit of nighttime monthly average Bias has reach to the maximum underestimation in March, and the maximum underestimation of the monthly average Bias has appeared in May. However, in the high and 
medium solar activity, the upper limit of nighttime monthly average Bias and the monthly average Bias showed were reached the maximum underestimation in April and October. The lower limit of nighttime monthly average Bias showed an annual variation in those three solar activities. In the low solar activity, the nighttime TEC of Klobuchar model has been fixed, which it larger than the actual ionospheric TEC. The Klobuchar model overestimates the actual ionosphere in January, April, August and December in medium solar activity, and it also overestimates the actual ionosphere in January, February, September and December in the high solar activity.

Figure $6(\mathrm{~g}), 6(\mathrm{~h})$ and $6(\mathrm{i})$ were the monthly average RMS at nighttime. In the high and medium solar activity, the maximum monthly mean RMS and mean RMS at nighttime have a half-year cycle, they reached the maximum in April and October, and the maximum in April was larger than in October. But the minimum monthly mean RMS is only has an annual variation. In addition, the maximum monthly mean RMS, minimum monthly mean RMS and monthly mean RMS have a common change, and they reached the minimum in June. These further illustrate the influence of the nighttime RMS and Bias on solar activity.

\section{SUMMARIES}

The Klobuchar model has been widely used by single-frequency GPS users to mitigate the effect of ionospheric delay. The constant value 9.23 TECU, meanwhile, has been generally admissive to describe the nighttime VTEC, which could introduce $20-30 \%$ errors. Therefore, it is of great significance to evaluate the nighttime accuracy of Klobuchar model in China. In this paper, The GIM provided by the IGS Center from 2008 to 2018 was treated as reference values to analyze the nighttime accuracy of the Klobuchar model. The results show as follows:

In terms of the 11-year solar cycle, the nighttime accuracy of the Klobuchar model is related to the solar activity, which is best in medium solar activity and worst in high solar activity. The Bias and RMS at nighttime are positive relation with the solar activity, it is largest in high solar activity and lowest in low solar activity. In addition, the nighttime Bias and RMS decrease with the increasing of latitudes in high and medium solar activity, and increase with the increasing of latitudes in low solar activity.

The nighttime accuracy, Bias and RMS of the Klobuchar model has a seasonal variations. The nighttime accuracy of Klobuchar model is best in winter, but it is best in summer and worst in winter during the medium and low solar activity. The Bias and RMS is largest in spring and lowest in summer during the high and medium solar activity, while they are largest in winter during low solar activity.

In term of Annual variation, the nighttime accuracy of the Klobuchar model is worst in April and May during high and medium solar activity, but it is best in May and June in the low solar activity. The range of accuracy increases with the increasing level of solar activity. Besides, the nighttime RMS of the Klobuchar model shows a first decrease and then an increase in the low solar activity. The nighttime Bias and RMS of the Klobuchar model show significant semi-annual variation during high and medium solar activity.

\section{ACKNOWLEDGEMENTS}

This work was sponsored by the National Natural Foundation of China (41664002;41704027); Guangxi Natural Science Foundation of China (2018GXNSFAA294045; 2017GXNSFDA198016; 2017GXNSFBA198139); the "Ba Gui Scholars" program of the provincial government of Guangxi; and the Guangxi Key Laboratory of Spatial Information and Geomatics (14-045-24-10;16-380-25-01)

\section{REFERENCES}

CAI C H, LIU L L, LI J Y, et al. Establishment of region ionospheric delay model in Nanning based on improved Klobuchar model [J].Journal of Geodesy and Geodynamics, 2015, 35 (5) :797-800.

Klobuchar JA. Ionospheric Time-delay Algorithm for Single-frequency GPS Users [J]. IEEE Transactions on Aerospace \& Electronic Systems, 2007, AES-23(3): 325-331.

Li M, Yuan Y, Wang N, et al. Performance of various predicted GNSS global ionospheric maps relative to GPS and JASON TEC data[J]. GPS Solutions, 2018, 22(2):55. 
LIU C, LIU C J, FENG X, et al. Klobuchar-like model suitable for different scales area [J]. Acta Geodaetica et Cartographica Sinica, 2016, 45 (S2) :54-63.

Liu Libo, Wan Weixing, Chen Yiding. The Relationship between Ionosphere and Solar Activity [J]. Chinese Science Bulletin, 2011, 56(7): 477-487.

Luo W, Liu Z, Li M. A preliminary evaluation of the performance of multiple ionospheric models in low-and mid-latitude regions of China in 2010-2011[J]. GPS Solutions, 2014, 18(2): 297-308.

RUAN Rengui, WU Xianbing, FENG Laiping, et, al. Single-Frequency Precise Point Positioning with Simultaneous Ionosperic Delay Estimation [J]. Acta Geodaetica et Cartographica Sinica, 2012, 41(4): 490-495.

WANG Jun, DANG Yamin, XUE Shuqiang. Application of a new ionospheric model-NeQuick in China [J]. Science of Surveying and Mapping, 2007, 32(4), 38-40.

WANG N B, YUAN Y B, LI Z S, et al. Improvement of Klobuchar model for GNSS single-frequency ionospheric delay corrections [J].Advances in Space Research, 2016, 57 (7) :1555-1569.

WU F B, ZHANG X H. Improving the Klobuchar model based on Beidou observations in Australia [J].Journal of Geodesy and Geodynamics, 2015, 35 (6) :1012-1016.

XU L B, CAI C L, CHEN G X, et al. A new Klobuchar model and its precision analysis for Beidou navigation satellite system [J].Journal of Geodesy and Geodynamics, 2015, 35 (5) :788-792.

ZHANG H P. Research on regional ionospheric monitoring and delay correction in China based on ground-based GPS [D]. Shanghai: Graduate University of the Chinese Academy of Sciences, 2006:79-85.

ZHAO W, ZHANG C Y. Practical analysis and improvement of Klobuchar model [J].Chinese Journal of Space Science, 2013, 33 (6) :624-628.
ZHU J. Research of astronomy and geodetic VLBI physical model [D].Nanjing: Nanjing University, 1991:1.-78. 